\title{
Phytochemical Composition and In vitro Antimicrobial, Antioxidant Activites of Methanolic Leaf Extracts From Excoecaria agallocha
}

\author{
A.A. Laith ${ }^{1,2 *}$, A.G. Mazlan', A.W. Effendy ${ }^{1}$, M.A. Ambak ${ }^{2}$, M. Nadirah', ${ }^{1,2}$, \\ T.S.Muhammad ${ }^{3}$, S.M.Zain ${ }^{4}$, A. Jabar ${ }^{5}$ and M. Najiah ${ }^{1,2}$ \\ ${ }^{1}$ School of Fisheries and Aquaculture Sciences, \\ Universiti Malaysia Terengganu, 21030 Kuala Terengganu, Malaysia. \\ ${ }^{2}$ Institute of Tropical Aquaculture (Aquatrop), \\ Universiti Malaysia Terengganu, 21030 Kuala Terengganu, Malaysia. \\ ${ }^{3}$ Institute of marine biotechnology, Universiti Malaysia Terengganu, 21030 Terengganu, Malaysia. \\ ${ }^{4}$ Agriculture and Food Science, Universiti Malaysia Terengganu, 21030 Terengganu, Malaysia. \\ ${ }^{5}$ Zhejiang University, School of Medicine, 866YuHuangTang Road, Hangzhou, China.
}

http://dx.doi.org/10.13005/bbra/2070

(Received: 01 January 2016; accepted: 16 February 2016)

\begin{abstract}
This study investigated the phytochemical, antimicrobial and antioxidant properties of methanolic leaf fractionated extracts of Excoecaria agallocha. Antibacterial activity test of fractionated extract of Excoecaria agallocha was conducted via Disk diffusion assay. Micro titer broth dilution technique was performed to determine the minimum inhibitory concentration (MIC) and Minimum Bactericidal Concentration (MBC). Qualitative and quantitative DPPH radical scavenging activity determines the antioxidant activity in E. agallocha. Chromatographic separation was completed using thin layer chromatography (TLC) and column chromatographic techniques. Phytochemical screening of fractionated extract revealed active constituents including alkaloids, saponins, flavonoids, terpenoid and tannins. In vitro antibacterial activity of columnfractionated extract demonstrated inhibitory effect against Flavobacterium indicum, Chryseobacterium meningosepticum, Chryseobacterium indologenes and Chryseobacterium gleum isolated from diseased fish. MIC and MBC of E. agallocha fractionated extract was $1.56 \mathrm{mg} / \mathrm{ml}$ and $3.12 \mathrm{mg} / \mathrm{ml}$, respectively. TLC-based qualitative DPPH analysis revealed antioxidant activity in $E$. agallocha extract, specified by yellowish stain on maroon color TLC plate. These bands indicate the presence of various compounds that could act as potential antimicrobial agents. The present study indicates that $E$. agallocha leaves contain active phytochemicals which inhibit bacteria and could be useful in the treatment of microbial infections in fish.
\end{abstract}

Key words: Excoecaria agallocha, Antibacterial, Antioxidants, Bacteria, TLC profiling.

A significant increase in the use of antimicrobial drugs for the control and treatment of disease-related issues in fish farming has been observed $^{1}$. Plant-based medicines are currently playing a major role in the treatment of disease

\footnotetext{
* To whom all correspondence should be addressed. H/P: 017-9326941;

E-mail: laith.abdul@umt.edu.my
}

due to minimally observed side effects. Extracts from mangroves and mangrove-associated species have proven to possess antimicrobial activities against humans, animals, and plant pathogens ${ }^{2}$. One mangrove species, Excoecaria agallocha (Euphorbiaceae) has been widely used in traditional medicine ${ }^{3}$. The bark and wood of this species have been used for the treatment of flatulence in Thailand, whereas the leaves and latex are used as fish poison 
in India ${ }^{4}$. Furthermore, in Pakistan the latex has been used as a remedy for ulcers, rheumatism, leprosy and paralysis ${ }^{5}$. In Sri Lanka, smoke from burning E. agallocha wood is used for leprosy treatment, and the root, when minced with ginger, is used for embrocating swollen hands and feet ${ }^{6}$. Despite these therapeutic uses for E. agallocha, it has been recognized to contain skin irritants. Interactions with skin may trigger inflammation and produce quick blistering; in addition, contact with eyes can cause temporary blindness ${ }^{7}$. Recently, ${ }^{8}$ revealed the potential bioactivities of metabolites from mangroves are a good remedy for a number of ailments such as headache, abdominal troubles, and skin diseases. Moreover, mangroves have many bioactivities such as antioxidant, antibacterial, antiviral, and anticancer due to the presence of numerous phytochemicals ${ }^{9,10,11}$. The anti-oxidative activity of $E$. agallocha leaf extract was investigated and the results suggested that environmental plants exposed to strong sunlight might require an efficient antioxidant system ${ }^{12}$. Previously, ethanol extract of E. agallocha showed significant antioxidant activity ${ }^{13,14}$. While methanolic crude extract of E. agallocha leaves had antioxidant and antibacterial activity ${ }^{8,15,16}$. Thus, considering the biomedical importance of mangroves, the present study was carried out to determine the phytochemical, antimicrobial and antioxidant properties of E.agallocha leaf extract.

\section{MATERIALSAND METHODS}

\section{Microorganisms}

Fish bacterial stocks were obtained from Fish Disease Laboratory, University Malaysia Terengganu (UMT) Malaysia. They include: Flavobacterium indicum, Chryseobacterium indologenes, Chryseobacterium gleum and Elizabethkingia meningoseptica (Chryseobacterium spp, Elizabethkingia spp, previously put under Flavobacterium family).

\section{Collection and extraction}

The leaves of Excoecaria agallocha were collected from rural areas in Terengganu, Malaysia (5Ú24'38.29Ú N and 103Ú05'31.32Ú E). The plant was identified at the Plant Taxonomy Laboratory, University Malaysia Terengganu (UMT). The extract of E. agallocha was prepared by standardized procedure as described by ${ }^{17}$.

\section{Phytochemical screening}

The methanol extract underwent chemical tests were carried out to identify the constituents using previously described procedures by ${ }^{18}$.

\section{Antibacterial Assay \\ Disk diffusion assay}

Disk diffusion assay was carried out on Anacker and Ordal's agar (EAOA) following the method described by ${ }^{19}$. Briefly, the disc (6 $\mathrm{mm}$ in diameter) was infused with $10 \mathrm{mg} / \mathrm{ml}$ extract (20 ìg / disc) and placed on inoculated agar. Antibiotic disc was used as positive control (Flumequine 30 ìg disc), and discs impregnated with $20 \mathrm{il}$ of methanol was used as negative controls. Discs were then air dried and placed equidistantly onto the surface of the pathogen seeded on Anacker and Ordal's agar (EAOA) and incubated at $28^{\circ} \mathrm{C}$ for $48 \mathrm{~h}$. The growth inhibition was assessed as the diameter ( $\mathrm{mm}$ ) of the inhibition zone around the discs. The experiment was carried out in triplicate.

\section{Determination of Minimum inhibitory concentration (MIC)}

The minimum inhibition concentration (MIC) of the crude extracts was determined for active component that showed antimicrobial activity against test organisms. The micro titer broth dilution technique was performed according to standards methods using sterile 96 well-micro titer plates ${ }^{20}$. Bacteria were cultured overnight in Anacker and Ordal's broth (EAOB) at $28^{\circ} \mathrm{C}$ and adjusted to achieve a turbidity of 0.5 McFarland $1.5 \times 10^{8} \mathrm{CFUmL}^{-1}$. A 100 il of Anacker and Ordal's broth (EAOB) were allocated to each wells. For each assay, the first wells were inoculate with 100 il of $100 \mathrm{mg} / \mathrm{ml}$ crude extracts, followed by the two fold dilution until $0.098 \mathrm{mg} / \mathrm{ml}$. Microbial suspensions of 10 ìl were used as inoculants. Positive growth control included broth and inoculums (without extracts suspension). Micro titer plates were sealed with parafilm to ensure the bacteria does not become dehydrated. Plates were further incubated at $28^{\circ} \mathrm{C}$ for $48 \mathrm{~h}$. After incubation, turbidity of each wells were observed visually and the optical density (OD) were measured at $540 \mathrm{~nm}$ by a micro titre reader model 680 (Bio-rad, US). Dilution values lower than the yielding value e" 2 than the doubling concentrations were interpreted as MIC results. The results were confirmed with micro dilution assays with the addition of 10 il of $0.1 \%$ 2, 3, 5-Triphenyltetrazolium chloride (TTC) 
(w/v) (Merck, Germany) into each well and incubated for $1 \mathrm{~h}$ for reaction. Color changes from purple to pink were observed visually where the bacteria were able to reduce the TTC into formazan. The lowest concentrations that inhibit the growth of bacteria with the absence of visual color changes were recorded as MIC. Tests were run in triplicate. Determination of Minimum bactericidal concentrations (MBC)

MBC extract was determined according to ${ }^{21}$. Plates that displayed negative results from the MIC assay were taken as samples and subcultured onto a new Anacker and Ordal's agar (EAOA) and were incubated at $28^{\circ} \mathrm{C}$ for $48 \mathrm{~h}$. The MBC inhibited bacterial growth on the agar plate surface and is therefore the lowest extract concentration. Experiments were performed in triplicate, and the mean readings were recorded. If ratio of MBC/MIC was d" 2, the active crude extract was considered as bactericidal; if not, it was considered as bacteriostatic. If the ratio was e"16, then the active crude extract is considered to be ineffective ${ }^{22}$.

Determination of antioxidant properties Qualitative DPPH radical scavenging activity

Silica gel sheets were left to air-dry and then sprayed with a $0.5 \%$ solution of 2, 2-Diphenyl1-picrylhydrazyl (methanolic DPPH) (SigmaAldrich, Germany). After a time lapse of $0.5 \mathrm{~h}$, antioxidant activity was detected as a pale-yellow stain on the purple background ${ }^{23}$.

Quantitative DPPH radical scavenging activity

Methanolic DPPH was used to determine the scavenging activity of extracts. This activity was measured through the bleaching of the purple color methanol solution as described by ${ }^{24}$.

\section{Chromatographic Characterization}

Analytical thin layer chromatography $(2 \mu \mathrm{l}$ of $1 \mathrm{mg} / \mathrm{ml}$ extracts) was performed on TLC silica gel kiesel gel 60 F254 (Art No. 1.05735.0001 Merck, Germany). Silica gel 60 F254 chloroform-ethyl acetate 9:1 (v/v) acts as a mobile phase in a presaturated solvent chamber by using Whatman filter paper No. 1 (Maidstone, UK). TLC was developed $1 \mathrm{~cm}$ from the bottom of the plates until the solvent front reached $1 \mathrm{~cm}$ from the top of the plates as described by ${ }^{25}$.

Column Packing and Fractionation

Approximately 220,000 mg of Kiesel silica gel (0.040 - 0.063 mm; 70 - 230 mesh ASTM) (Merck, Germany) were packed into a $250 \mathrm{ml}$ chromatography column using hexane as eluent, tapped slowly and left overnight. Silica gel acted as the stationary phase, while solvents the mobile phase as described by ${ }^{26}$.

\section{Statistical analysis}

Data were expressed as mean \pm standard deviation of triplicate measurements. Analysis of variance (ANOVA) and the mean was compared with least significant difference $(\mathrm{P}<0.05)$ using Gestate 12.1 program.

\section{RESULTS}

\section{Extraction and Solvent Partitioning of $E$. agallocha}

A total of 6 crude extracts were obtained from methanolic crude extracts of E. agallocha. The highest extraction yield was found in methanol partitions with a value of $23,110 \mathrm{mg}$, while hexane partitions gave the lowest extraction yield of 0.500 mg (Table 1).

\section{Phytochemical screening of E. agallocha}

Phytochemical studies showed $E$. agallocha leaf extracts contained a variety of phytochemical constituents including: tannins, flavonoids, steroid, tarpenoid, and saponin (Table 2).

In vitro Antimicrobial activity of extracts of $E$. agallocha against bacteria samples

The present study used two isolates of E. meningoseptica, from e kidney and skin diseased fish. In addition, three species from the same family (C. gleum, C. indologenese and F. indicum) were isolated from diseased fish in Malaysia. The mean zone of inhibition for E. agallocha fractions 1, 2, 3, 4,5 and 6 on bacterial tested in this study ranged from 0 - 6, 0 - 11, 0 - 8, 0 - 17, 6-23, and 8 - $28 \mathrm{~mm}$, respectively. The lowest mean inhibition zone recorded was fraction 1 , while the highest mean inhibition zone recorded was fraction 6 . There was a significant difference $(\mathrm{P}<0.05)$ among fractions (Figure 1).

Minimum Inhibitory Concentration (MIC) and Minimum Bactericidal Concentration (MBC)

The antimicrobial activities of the extracts were quantitatively assessed by determining the MIC and MBC, respectively. Fractions 5 and 6 showed the lowest MIC and MBC value at 1.56 
and $3.12 \mathrm{mg} / \mathrm{ml}$, respectively. These results were statistically significant $(\mathrm{P}<0.05)$ compare with other fractions (Table 3).

\section{Antioxidant tests}

\section{Qualitative DPPH radical scavenging activity}

Color changes were observed on Silica

Gel G plates when methanolic extracts of $E$. agallocha $(5 \mu \mathrm{l})$ were spotted at the bottom of the plate and sprayed with DPPH. Yellow spots on the purple color of DPPH reagents on TLC indicate positive antioxidant activity (Figure 2).

\section{Antioxidant (Quantitative analysis)}

Quantitative analysis of E. agallocha antioxidant activity was carried out using vitamin C (ascorbic acid) as a standard reference. Higher concentrations of plant extracts produced higher antioxidant activity with R2 value, which is 0.970 (Figure 3). According to the graph, at a concentration of $0.5 \mathrm{mg} / \mathrm{ml}$, vitamin C can achieve level 2 antioxidant activities. However, extracts of E. agallocha need to be at a higher concentration to achieve the same level of antioxidant activity as vitamin C.

\section{TLC Profiling of $E$. agallocha leaf extracts}

TLC profiles indicated the presence of phytochemical compounds in E. agallocha leaf extracts. Variation of different values of the retention factor $\left(\mathrm{R}_{\mathrm{f}}\right)$ was the initial step in selecting the appropriate solvent for specific compound isolation, regarding their polarity index value. In this study, TLC profiling of E. agallocha was developed by different solvent mixtures in the

Table 1. Percentage yield of the methanolic extract of Excoecaria agallocha leaves

\begin{tabular}{lccc}
\hline Fractions & Ratio & Percentage & Weight (mg)* \\
\hline Hexane & $100 \%$ & $0.21 \%$ & 0.5 \\
Hexane: Chloroform & $1: 1$ & $0.04 \%$ & 0.09 \\
Chloroform & $100 \%$ & $0.08 \%$ & 0.19 \\
Chloroform: Ethylacetate & $1: 1$ & $2.83 \%$ & 6.73 \\
Ethylacetate & $100 \%$ & $2.24 \%$ & 5.33 \\
Methanol & $100 \%$ & $9.71 \%$ & 23.11 \\
\hline
\end{tabular}

*Values were calculated with respect to the amount of the methanolic crude extract

Table 2. Preliminary phytochemical analysis of Excoecaria agallocha leaf extracts and Solvent Partitionin

\begin{tabular}{lllllllll}
\hline S. & Secondary metabolites & \multicolumn{7}{c}{ Excoecaria agallocha leaves extracts } \\
\cline { 3 - 8 } No. & & F1 & F2 & F3 & F4 & F5 & F6 & Leaf Extracts \\
\hline 1 & Carbohydrates & - & - & - & - & - & - & - \\
2 & Anthraquinones & - & - & - & - & - & - & - \\
3 & Terpenoids & - & - & + & + & + & + & + \\
4 & Flavonoids & - & + & - & + & + & + & + \\
5 & Saponins & - & - & - & - & - & - & - \\
6 & Tannins & + & - & + & + & + & + & + \\
7 & Alkaloids & + & + & + & + & + & + & + \\
8 & Steroids & - & + & - & + & - & - & - \\
9 & Cardiac glycosides & - & - & - & - & - & - & - \\
10 & Fixed oil & - & - & - & - & - & - & + \\
11 & Protein & + & + & + & - & + & + & + \\
12 & Fat & - & - & - & - & - & + & + \\
13 & Gum & + & + & + & + & + & + & + \\
14 & Lingin & - & - & - & - & + & + & + \\
15 & Volatile oil & - & - & - & - & - & - & - \\
\hline
\end{tabular}


visualization of short wave, long wave UV, iodine vapors and sprayed reagents; e.g., Anisaldehydesulphuric reagents, dragendroff's reagents, and $\mathrm{FeCl}_{3}$ reagents. For the determination of antioxidant properties, the developed TLCs were left to air-dry for $0.25 \mathrm{~h}$ and then soaked in a $0.04 \%(\mathrm{w} / \mathrm{v})$ solution of 1, 1-diphenyl-2-picrylhydrazyl (DPPH) of methanol. Retention factor $\left(\mathrm{R}_{\mathrm{f}}\right)$ of methanol crude extracts of E. agallocha were detailed (Figure 4).

\section{Retention factor $\left(\mathbf{R}_{\mathrm{f}}\right)$}

The methanol crude extracts of $E$. agallocha leaves with the mobile phases of ethyl acetate- chloroform (2:8) successfully separated the compounds with the retention factor $\left(\mathrm{R}_{\mathrm{f}}\right)$. Shortwave $R_{f}$ values were; $R_{f} 1: 0.96, R_{f} 2: 0.84, R_{f}$
3: 0.66, $\mathrm{R}_{\mathrm{f}} 4: 0.52, \mathrm{R}_{\mathrm{f}} 5: 0.42, \mathrm{R}_{\mathrm{f}} 6: 0.28, \mathrm{R}_{\mathrm{f}} 7: 0.1$. Long-wave $R_{f}$ values; $R_{f} 1: 0.96, R_{f} 2: 0.80, R_{f} 3$ : $0.70, R_{f} 4: 0.62, R_{f} 5: 0.40, R_{f} 6: 0.26, R_{f} 7: 0.1$. AS reagent $R_{f}$ values; $R_{f} 1: 0.96, R_{f} 2: 0.80, R_{f} 3: 0.64$. Iodide $\mathrm{R}_{\mathrm{f}}$ values; $\mathrm{R}_{\mathrm{f}} 1: 0.96, \mathrm{R}_{\mathrm{f}} 2: 0.84, \mathrm{R}_{\mathrm{f}} 3: 0.66, \mathrm{R}_{\mathrm{f}}$ 4: $0.46, R_{f} 5: 0.3, R_{f} 6: 0.14$. The ranges of the 4 were between $0.24-0.96$. A total of 10 spots were identified encompassing 7 unique colors (Black, Pink, Brown, Purple, Blue, Yellow and Green). These spots were developed visually (Figure 5).

Phenolic compounds were a major component in the E. agallocha ethyl acetate fraction at the $R_{f}$ value of 0.70 and 0.80 . Three fractions, hexane with solvent system hexane: chloroform, chloroform with solvent system

Table 3. Minimal inhibitory concentration (MIC) and minimal bactericidal concentration (MBC) $(\mathrm{mg} / \mathrm{ml})$ for the fraction

\begin{tabular}{|c|c|c|c|c|c|c|c|c|c|c|c|c|}
\hline \multirow[t]{2}{*}{ Strain } & \multicolumn{2}{|c|}{ Fraction1 } & \multicolumn{2}{|c|}{ Fraction2 } & \multicolumn{2}{|c|}{ Fraction3 } & \multicolumn{2}{|c|}{ Faction 4} & \multicolumn{2}{|c|}{ Fraction 5} & \multicolumn{2}{|c|}{ Fraction6 } \\
\hline & MIC & MBC & MIC & MBC & MIC & $\mathrm{MBC}$ & MIC & $\mathrm{MBC}$ & MIC & MBC & MIC & MBC \\
\hline 1 & $0.0 \mathrm{a}$ & $0.0 \mathrm{a}$ & $25 b$ & $50 \mathrm{c}$ & $12.5 \mathrm{~d}$ & $25 b$ & $6.25 \mathrm{e}$ & $12.5 \mathrm{~d}$ & $3.12 f$ & $6.25 \mathrm{e}$ & $3.12 f$ & $6.25 \mathrm{e}$ \\
\hline 2 & $0.0 \mathrm{a}$ & $0.0 \mathrm{a}$ & $25 b$ & 50c & $25 b$ & 50c & $3.12 \mathrm{f}$ & $6.25 \mathrm{e}$ & $3.12 \mathrm{f}$ & $6.25 \mathrm{e}$ & $3.12 \mathrm{f}$ & $6.25 \mathrm{e}$ \\
\hline 3 & $0.0 \mathrm{a}$ & $0.0 \mathrm{a}$ & $25 b$ & $50 c$ & $25 b$ & $50 c$ & $3.12 \mathrm{f}$ & $6.25 \mathrm{e}$ & $3.12 f$ & $6.25 \mathrm{e}$ & $3.12 \mathrm{f}$ & $6.25 \mathrm{e}$ \\
\hline 4 & $0.0 \mathrm{a}$ & $0.0 \mathrm{a}$ & $25 b$ & $50 \mathrm{c}$ & $12.5 \mathrm{~d}$ & $25 b$ & $3.12 f$ & $6.25 \mathrm{e}$ & $1.56 \mathrm{~g}$ & $3.12 \mathrm{f}$ & $1.56 \mathrm{~g}$ & $3.12 \mathrm{f}$ \\
\hline 5 & $25 b$ & 50c & $25 b$ & $50 \mathrm{c}$ & $12.5 \mathrm{~d}$ & $25 b$ & $3.12 \mathrm{f}$ & $3.12 f$ & $1.56 \mathrm{~g}$ & $3.12 \mathrm{f}$ & $1.56 \mathrm{~g}$ & $3.12 \mathrm{f}$ \\
\hline
\end{tabular}

1 (F.indicum), 2 (E.meningoseptica -kidney), 3 (E.meningoseptica -skin), 4 (C. gleum) 5 (C .indologenes) Different letter show significant differences $(\mathrm{P}<0.05)$

Table 4. Thin layer chromatography resolution of the fraction of the methanolic extract of Excoecaria agallocha leaves

\begin{tabular}{lllll}
\hline Fractions & Solvent System & Ratio & No. of Spots & $\mathrm{R}_{\mathrm{f}}$ value \\
\hline Hexane & Hexane: Chloroform & $4: 6$ & 4 & {$[0.56,0.58,0.71,0.94]$} \\
Hexane: Chloroform & Hexane: Methanol & $9: 1$ & 2 & {$[0.19,0.53]$} \\
Chloroform & Hexane: Chloroform & $4: 6$ & 4 & {$[0.42,0.52,0.64,0.94]$} \\
Chloroform: Ethyl acetate & Chloroform: Methanol & $9: 1$ & 4 & {$[0.68,0.82,0.96,0.98]$} \\
Ethyl acetate & Dichloromethane: Methanol & $1: 9$ & 2 & {$[0.67,0.74]$} \\
Methanol & Dichloromethane: Methanol & $3: 7$ & 3 & {$[0.70,0.80,0.88]$} \\
Extract & Chloroform: Ethyl acetate & $8: 2$ & 7 & {$[0.14,0.32,0.5,0.6$,} \\
& & & & $0.74,0.9,0.96]$ \\
\hline
\end{tabular}

hexane: chloroform and chloroform: ethyl acetate with solvent system chloroform: methanol, revealed four evident spots. Two fractions, ethyl acetate with solvent system dichloromethane: methanol and hexane chloroform with solvent system hexane: methanol revealed two evident spots. Three spots were observed on the methanol fraction with solvent system dichloromethane: methanol. The range of the $R_{f}$ value was 0.24 - 0.96 (Table 4).

\section{DISCUSSION}

The results of this explorative experience with crude extracts of Excoecaria agallocha have 
been contained tannins, flavonoids, steroid, tarpenoid, and saponin. On the other hand, the result of this work indicates that the significant differences within fractions may be attributed to the mangrove-plant extracts and their antimicrobial activity against pathogenic bacterial strains. Our observations in this study in accordance to the results of previous studies by ${ }^{16,17,27,28}$ indicated that E. agallocha leaf extracts displayed antimicrobial activity.

Based on disc diffusion results, methanolic crude extract of E. agallocha leaves are in agreement with the result of ${ }^{29}$ showed that biological activity test of mangrove E. agallocha crude extract against Vibrio mimicus and V. Costicola of inhibition zone on diffusion agar was $10.35 \pm 0.05$ and $12.6 \pm 0.05 \mathrm{~mm}$, respectively.

The results of present study are corroborated by the findings of ${ }^{28}$ reported that the mangrove leaf extracts of $E$. agallocha showed maximum inhibitory activity was $18 \mathrm{~mm}$ against Streptoccocus aureus. The diameters of the zone of inhibition shown by the methanol extract against the pathogenic bacteria in this study were similar to the finding by ${ }^{30}$.

The present results revealed $E$. agallocha minimal inhibition concentration (MIC) value was $1.56 \mathrm{mg} / \mathrm{ml}$, and the minimal bactericidal concentration (MBC) value was $3.12 \mathrm{mg} / \mathrm{ml}$ against bacteria. In comparison with the result of the study of ${ }^{14}$ stated that the MIC of E. agallocha leaf extract ranged from 5 to $7 \mathrm{mg} / \mathrm{ml}$ against the following bacteria: Pseudomonas aeruginosa, Bacillus subtilis, Staphylococcus epidermidis, Staphylococcus aureus, Vibrio cholera, Shigella flexneri, Bacillus licheniformis, Bacillus brevis and Escherichia coli. Furthermore, the partitioned portions of methanolic extract of E. agallocha revealed the existence of tannins, flavonoids, alkaloids and saponins. These are compounds that are known to have various curative effects against most pathogenic organisms as reported by many researchers ${ }^{31,32}$. The results of the present study are corroborated by the findings of ${ }^{33}$ that the highest antibacterial activities in mangrove halophytes were due to the presence of high content of phenols, which include phytochemicals such as; alkaloids, tannins and flavonoids, are present in the E. agallocha extract. However, alkaloids have numerous functions including analgesics, anti-inflammatory, antispasmodic and bactericidal effects ${ }^{34}$. Moreover, tannins display anticancer activity and inhibition of cell protein synthesis ${ }^{35}$. Also, steroidal extracts displayed antibacterial activities ${ }^{36}$, while flavonoids exhibit antimicrobial and antioxidant properties ${ }^{37}$. Meanwhile, thin layer chromatography (TLC) analysis revealed a great potential for E. agallocha that appeared in the form of the many bands on the TLC-plates. Combinations of ethyl acetate and methanol solvents were used to carry out the TLC. All pure solvents separated into seven bands and showed the presence of phenolic compounds. The results of the present study are corroborated with previous findings of ${ }^{14,38}$ that TLC chromatograms of plant extracts showed the presence of phenolic compounds, such as tannins and flavonoids and these compounds possess diverse biological properties such as anti-inflammatory, anti-bacterial and antioxidant activities. Supporting the results of the present study, ${ }^{39}$ showed that E. agallocha bark fractions were a potential source of antioxidants and various phytochemicals give different $R f$ values in different solvent system. This variation in $\mathrm{Rf}$ values of the phytochemicals provides a very important clue in the understanding of their polarity and also helps in selection of appropriate solvent system for separation of pure compounds by column chromatography. Compounds showing high $\mathrm{Rf}$ values in less polar solvent systems have low polarity and those with lower Rf value have high polarity. Mixtures of solvents with variable polarity in different ratios can be used for separation of pure compounds from plant extracts. The selection of appropriate solvent systems for particular plant extracts can only be achieved by analyzing the Rf values of compounds in different solvent system. Presently, TLC profiling using different solvent systems indicated the presence of diverse types of phytochemicals in these plants. Different Rf values observed for compounds also provide insight into their polarity. However, in the study of ${ }^{40}$ reported that the biochemical assays such as total antioxidant and DPPH scavenging potential are particularly suitable for the evaluation of antioxidant activity of crude extracts. E. agallocha crude extract was as potent as Vitamin C with a maximum inhibition of $97 \%$ at $0.5 \mathrm{mg} / \mathrm{ml}$ in comparison to $95 \%$ for vitamin C at equal 


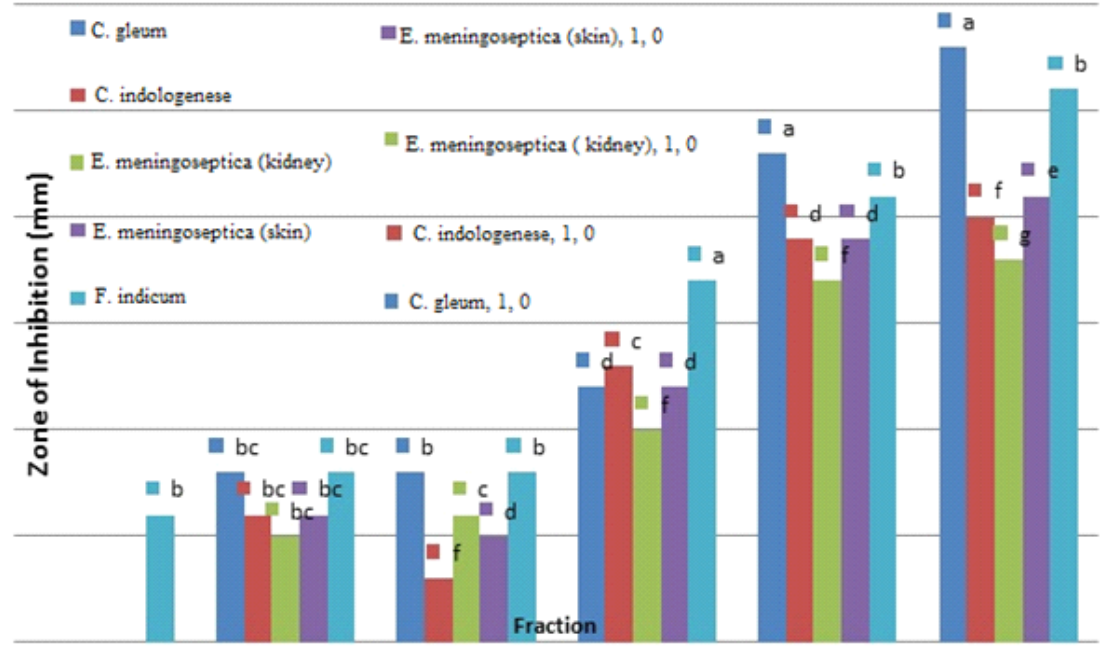

Fig. 1. Antibacterial activities of the fraction of Excoecaria agallocha against bacteria Different letter show significant differences $(\mathrm{p}<0.05)$

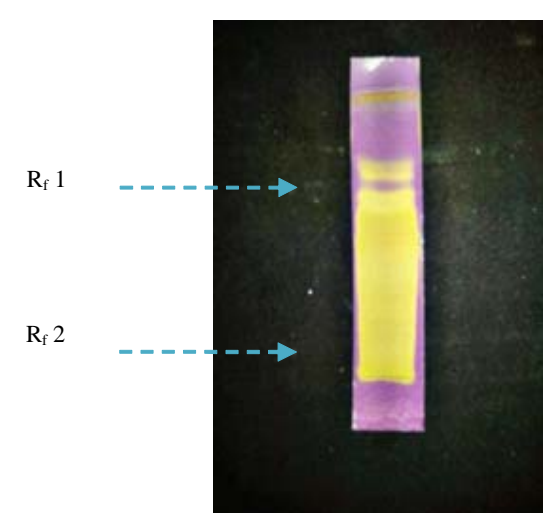

Fig. 2. Antioxidant activity of Excoecaria agallocha crude extract concentrations. Our findings were also similar to the findings of ${ }^{13}$ that the qualitative DPPH assay revealed the presence of significant antioxidant activity in the alcoholic extract of E. agallocha, specified by a yellowish stain on the maroon background of a TLC plate the authors suggested that E. agallocha may have a potential antioxidant effect according to the DPPH antioxidant assay results.

Hence, the result obtained in the present study shows that the methanolic extract of E. agallocha has potential antioxidant properties as in agreement with previous study by 14, 39, 41, 42 . Therefore, E. agallocha can be used as alternative to the antibiotics for the treatment or prevention of bacterial infections in fish.
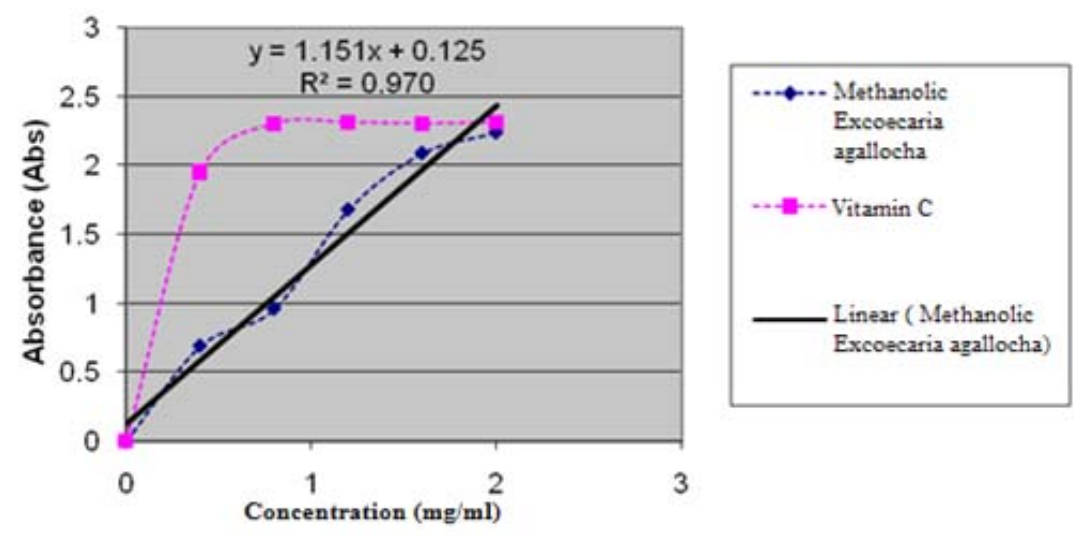

Fig. 3. Comparing antioxidant activity of Excoecaria agallocha with Vitamin 


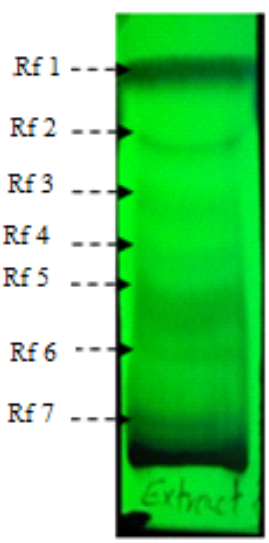

Short wave

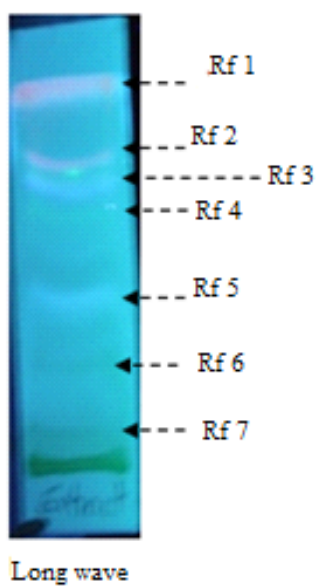

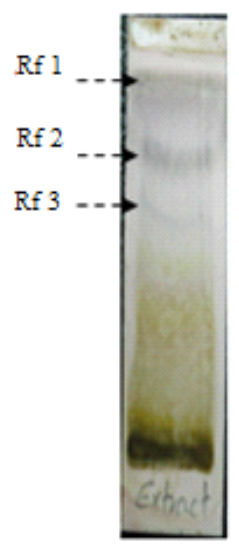

AS reagent

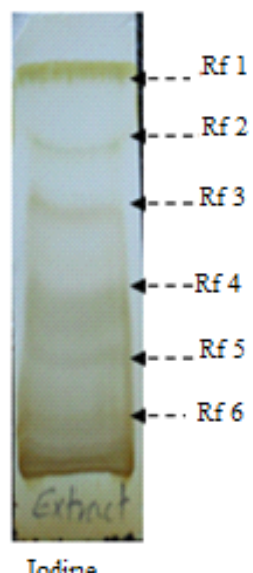

Iodine

Fig. 4. TLC fingerprinting of Excoecaria agallocha crude extracts ( $\mathrm{CHCL}_{3}$-EtOAc 8:2) on TLC silica gel kiesel gel $60 \mathrm{~F}_{254}$ (Art No. 1.05735.0001 Merck, Germany)

(a): UV 254 nm; (b): UV 366 nm; (c): anisaldehyde/sulphuric reagent; (e):Iodide.

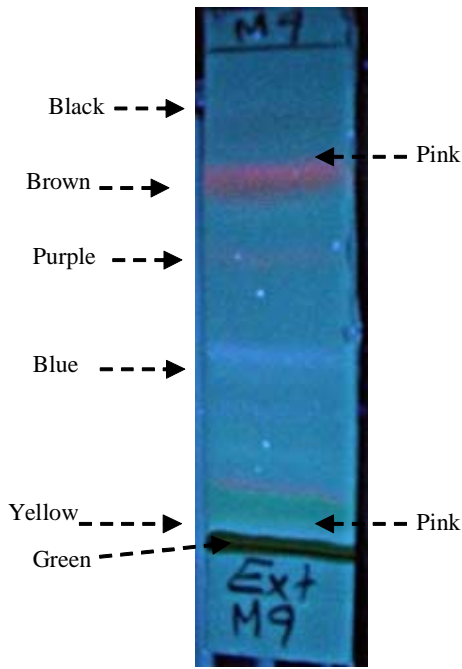

Fig. 5. TLC fingerprinting of the leaves crude extracts of Excoecaria agallocha $\left(\mathrm{CHCL}_{3}\right.$-EtOAc 8:2) on TLC silica gel kiesel gel $60 \mathrm{~F}_{254}$

\section{CONCLUSION}

The results of the present study concluded that the crude extract of selected mangrove plants is a good source of antimicrobial and antioxidant agents. However, further studies on the purification of bioactive compounds are currently under way to discover more effective solutions for treating diseases.

\section{ACKNOWLEDGEMENTS}

This project was supported by the Project Establishment of Research and Education Network on Coastal Marine Science in Southeast Asia, COMSEA. Grant No: 53177

\section{REFERENCES}

1. Rodgers, C.J., Furones, M.D. Antimicrobial agents in aquaculture: Practice, needs and issues. The use of veterinary drugs and vaccines in Mediterranean aquaculture. Zaragoza: CIHEAM, 2009; 86: 41 - 59.

2. Patra, J.K., Thatoi, H.N. Metabolic diversity and bioactivity screening of mangrove plants: a review. Acta. Physiol. Plant., 2011; 33: 1051 1061.

3. Patil, R.C., Sonal, M.M., Madhav, V.U., Katchi, V.I., Asha, J.R., Abhishek, M., Alpana, S.M. Anti-Reverse Transcriptase and Anticancer activity of stem ethanol extracts of Excoecaria agallocha (Euphorbiaceae). Ceylon Journal of Science (Bio. Sci.) 2011; 40: 147 - 155.

4. Karalai, C., Wiriyachitra, P., Operkuch, H.J., Hecker, E. Cryptic and free skin irritants of the daphnane and tigliane types in latex of Excoecaria agallocha. Planta Med., 1994; 60: $351-355$.

5. Thirunavukkarasu, P., Ramkumar, L., Ramanathan, T. Anti-ulcer Activity of Excoecaria agallocha bark on NSAID-induced Gastric Ulcer in Albino Rats. Global J. 
Pharmacol., 2009; 3: 123 - 126.

6. Jayaweera, D.M. Medicinal Plants (Indigenous and Exotic) used in Ceylon, Part 2: Natn. Sci. Coun. Sri Lanka; 1980.

7. Bandaranayake, W.M. Traditional and medicinal uses of mangroves. Mangroves and Salt Marshes, 1998; 2: 133 - 48.

8. Singh, C.R., Kathiresan, K., Sekaranandhan, S., Suganthi, K.K. Antioxidant and Antibacterial Activity of Field Grown and Tissue Cultured Root Callus of Mangrove Species. European J. Med. Plants., 2014;4:723-742.

9. Yin, B.W., Shen, L.R., Zhang, M.L., Zhao, L., Wang, Y.L., Huo, C.H., Shi, Q.W. Chemical Constituents of Plants from the Genus Excoecaria. Chemistry \& Biodiversity., 2008; 5: 2356 - 2371.

10. Boopathy, N.S., Kathiresan, K. Anticancer Drugs from Marine Flora: An Overview. J. Oncol., 2011; 18: 201 - 320.

11. Kumar, P.P. Anticancer activity of Excoecaria agallocha leaf extract in cell line model. Int. $J$. Pharm. Bio. Sci., 2013; 3: 392 - 398.

12. Masuda, T., Yonemori, S., Oyama, Y., Takeda, Y., Tanaka, T., Andoh, T., Shinohara, A., Nakata, M. Evaluation of the Antioxidant Activity of Environmental Plants: Activity of the Leaf Extracts from Seashore Plants. J. Agric. Food. Chem., 1999; 4: 1749 - 1754.

13. Subhan, N., Ashrafulalam, M., Ahmed, F., Abdul Awal, M., Nahar, L., Sarker, S.D. In vitro antioxidant property of the extract of Excoecaria agallocha (Euphorbiaceae), DARU. J. Pharm. Sci., 2008; 16: 149 - 154.

14. Patra, J.K., Gouda, S., Sahoo, S.K., Thatoi, H.N. Chromatography separation, H NMR analysis and bioautography screening of methanol extract of Excoecaria agallocha L. from Bhitarkanika, Orissa, India. Asian Pac. J. Trop. Biomed., 2012; S50 - S56.

15. Poorna, C.A., Sathish, K.M., Santhoshkumar, T.R., Soniya, E.V. Phytochemical analysis and in vitro screening for biological activities of Acanthus ilicifolius. JPR, 2011; 4: 1977 - 1981.

16. Deepa, M., Padmaja, C.K. Preliminary phytochemical analysis and thin layer chromatography of the extracts of excoecaria agallocha. Int. J. Pharm. Sc. Res. 2014; 5: 45354542.

17. Laith, A.A., Najiah, M. Antimicrobial activities of blinding tree, Excoecaria agallocha against selected bacterial pathogens. J. Microbiol. Antimicrob., 2014; 6: 29 - 36.

18. Harbone, J.B. Methods of extraction and isolation. In: Phytochemical methods, Chapman and Hall: London, 1998; 60 - 66.
19. Barker, G.A., Kehoe, E. Assessment of disc diffusion methods for susceptibility testing of Aeromonas salmonicida. Aquacult. J., 1995; 134: 1 - 8.

20. Clinical Laboratory Standards Institute. Performance Standards for Antimicrobial Susceptibility Testing, Sixteenth Informational Supplement CLSI. Wayne: PA. USA, 2006; 26: M100 - S116.

21. Llavenil, S.B., Kaleeswaran, B., Kumar, S.R., Evaluation of antibacterial activity and phytochemical analysis of Crinum asiaticum. Int. J. Curr. Res., 2010; 1: 035 - 040.

22. Shanmughapriya, S., Manilal, A., Sujith, S., Selvin, J., Kiran, G., Natarajaseenivasan, K. Antimicrobial activity of seaweeds extracts against multi resistant pathogens. Ann Microbiol, 2008; 58: 535 - 541.

23. Takao, T., Kitatami, F., Watanabe, N., Yagi, A., Sakata, K. A simple screening method for antioxidants and isolation of several antioxidants produced by marine bacteria from fish and shellfish. Biosci. Biotech. Bioch., 1994; 58: 1780 $-1783$.

24. Alam-ripa, F., Nahar, L., Haque, M., Islam, M.M. Antibacterial, Cytotoxic and Antioxidant Activity of Crude Extract of Marsilea Quadrifoli.Eur. J. Sci. Res., 2009; 33:123-129.

25. Wagner, H., Bladt, S. Plant Drug Analysis, $2^{\text {nd }}$ edn. Berlin, Springer Verlag, 1996.

26. Abbot, D., Andrews, R.S. An Introduction to chromatography, 2nd edn. London: Longman press, 1970; 72-78.

27. Agoramoorthy, G., Chandrasekaran, M., Venkatesalu, V., Hsu, M.J. Antibacterial and Antifungal Activities of Fatty Acid Methyl Ester of Blind Your Eye Mangrove from India. $J$. Microbiol., 2007; 38 :739 - 742.

28. Kumar S.R, Ramanathan G, Subhakaran M, Inbaneson S.J., Antimicrobial compounds from marine halophytes for silkworm disease treatment. Int J Med MedSci, 2009; 1: 184 - 191.

29. Suryati, E., Hala, Y. Bioactive Substances of Mangrove Excoecaria agallocha as Shrimp Diseases Inhibitor. Mar. Chim. Acta, 2002; 1: 9 - 14.

30. Chandrasekaran, M., Kannathasan, K., Venkatesalu, V., Prabhakar, K. Antibacterial activity of some salt marsh halophytes and mangrove plants against methicillin resistant Staphylococcus aureus. World. J. microb. Biot., 2009; 25: 155 - 160.

31. Afolayan, A.J. Extracts from the shoots of Arctotis arctotoides inhibit the growth of bacteria and fungi. Pharm. Biol., 2003; 41: 22-25.

32. Usman, H., Abdulrahman, F.I., Ladan, A.H. 
Phytochemical and Antimicrobial Evaluation of Tribuluster restris L. (Zygophylaceae Growing in Nigeria). Res. J. Bio. Sci. Med. well Journals., 2007; 2: 244 - 247.

33. Mohaddese, M., Nastaran, K., Mona, M. Antimicrobial activity of Rosemary, Fennel and Galbanum essential oils against clinical isolates of Staphylococcus aureus. Biharean. Biol., 2011; 5(1): $4-7$.

34. Okwu, D.E., Josiah, C. Evaluation of the chemical composition of two Nigerian medicinal plants. Afr. J. Biotechnol., 2006; 5: 357 - 361.

35. Shimada, Y., Yonemura, S., Ohkura, H.H., Strutt, D., Uemura, T. Polarized transport of Frizzled along the planar microtubule arrays in Drosphilawing epithelium. Dev Cell., 2006; 209 - 222.

36. Quinlan, M.B., Quinlan, R.J., Nelan, J.M. Ethnophysiology and herbal treatments of intestinal worms in Dominica. West Indies. $J$. Ethno. Pharmacol., 2000; 80: 75 - 83.

37. Hodek, P., Trefil, P., Stiborova, M. Flavonoids - Potent and versatile biologically active compounds interacting with cytochrome P450.
Chemico. Biol. Intern., 2002; 139: 1 - 21.

38. Nagavani, V., Ragahava, R.T. Evaluation of antioxidant potential and identification of polyphenols by RP-HPLC in Michelia champacai flowers. Adv. Biol. Res., 2010; 4: 159 - 168.

39. Hossain, S.J., Aoshima, H., El-Sayed, M., Ahmed, F. Antioxidative and anti-histaminerelease activities of Excoecaria agallocha. L. Pharmacol. Online., 2009; 2: 927 - 936.

40. Poli, G., Leonarduzzi, G., Biasi, F., Chiarpotto, E. Oxidative stress and cell signaling. Curr. Med. Chem., 2004; 11: 1163 - 1182.

41. Nusrat, S., Mohammad, A., Firoj, A., Israt, J.S.L., Satyajit, N.D.S. Bioactivity of Excoecaria agallocha. Braz. J. Pharmacogn., 2008; 18: 521 - 526.

42. Rajaram, P., Arumugam, M., Pawar, U.R., Gomathinayagam, M., Lakshmanan, G.M.A. Antibacterial and antioxidant activity between micro propagated and field grown plants of Excoecaria agallocha L. Int. J. of Pharmacy., 2012; 3: 235 - 240. 